\title{
Influência da Monensina no Consumo e na Fermentação Ruminal em Bovinos Recebendo Dietas com Teores Baixo e Alto de Proteína
}

\author{
Marcus Vinicius Morais de Oliveira ${ }^{1}$, Rogério de Paula Lana ${ }^{2}$, Gulab N. Jham ${ }^{3}$, José Carlos \\ Pereira $^{4}$, Juan Ramón Olaquiaga Pérez ${ }^{5}$, Sebastião de Campos Valadares Filho ${ }^{4}$
}

\begin{abstract}
RESUMO - Foram utilizados quatro novilhos holandeses fistulados no rúmen e alimentados quatro vezes ao dia (8, 11, 14 e 17 h) com dietas contendo teores baixo e alto de proteína (baixo e alto), com e sem monensina, totalizando quatro dietas experimentais (tratamentos), com o intuito de se verificar a influência da monensina sobre o consumo e a fermentação ruminal. As dietas contendo teores de proteína possuíam, respectivamente, 11,4 e 16,5\% de proteína bruta na matéria seca e eram constituídas por 65\% de feno de capimbraquiária (Brachiaria decumbens) e 35\% de concentrado, sendo o concentrado da dieta com baixo teor protéico à base de milho e uréia e o da dieta com alto teor protéico à base de milho e farelo de soja. O nível de ionóforo utilizado foi de $28 \mathrm{mg}$ de monensina/kg de MS consumida. As amostras de líquido ruminal foram coletadas diariamente às $13 \mathrm{~h}$. Utilizou-se delineamento em quadrado latino, com quatro tratamentos (dietas) e quatro animais. As dietas com alto teor protéico proporcionaram aumento da concentração ruminal do ácido butírico e da amônia. O fornecimento de monensina sódica, independentemente do teor protéico das dietas, promoveu diminuição no consumo de matéria seca, aumento na concentração de ácido propiônico e redução do teor de ácido butírico, da relação acetato:propionato e da atividade específica de produção de amônia. A monensina, quando associada à dieta com baixo teor protéico, também ocasionou diminuição da concentração do ácido acético e elevação do pH e da síntese de proteína microbiana ruminal. Não foram observadas diferenças estatísticas significativas na concentração de amônia ruminal com a inclusão de monensina.
\end{abstract}

Palavras-chave: ácidos graxos voláteis, amônia, ionóforo, ruminantes

\section{Effects of Different Dietary Levels of Monensin and Protein on Intake and Ruminal Fermentation in Bovines}

ABSTRACT - Four ruminally fistulated Holstein steers were fed four times a day (8 a.m., 11 a.m., 2 p.m. and 5 p.m.) with four diets with low and high protein content, with or without monensin, to verify the effect of monensin on feed intake and ruminal fermentation. Diets contained (dry matter basis): low (11.4\%) and high (16.5\%) crude protein content, 65\% of brachiaria hay (Brachiaria decumbens) and $35 \%$ of concentrate. Corn and urea- and corn and soybean meal- based diets were, respectively, the concentrates of low and high protein content. The level of ionophore was of $28 \mathrm{mg}$ of monensin/ $\mathrm{kg}$ of DM intake. Samples of ruminal fluid were collected from the animals two hours post-feeding. The experiment was analyzed as a Latin square with four treatments and four animals. High protein content -based diets increased ruminal concentration of butyric acid and ammonia. Feeding of diets with monensin, independently of the protein content, decreased dry matter intake, increased propionic acid concentration and decreased butyric acid, acetate:propionate ratio and specific activity of ammonia production. Monensin with low protein content-based diet also decreased acetic acid concentration and incerased ruminal pH and microbial protein synthesis. No significant differences on the concentration of ruminal ammonia for diet with monensin were observed.

Key Words: ammonia, ionophore, ruminant, volatile fatty acid

\section{Introdução}

Ionóforos, como a monensina sódica, são compostos produzidos por bactérias, sobretudo do grupo Streptomyces cinnamonensis, que, sendo altamente lipofílicos e tóxicos a muitos microrganismos, são definidos como antibióticos (Haney \& Hoehn, 1967). No Brasil, a monensina sódica atualmente é comercializada pela empresa ELANCO com o nome de Rumensin ${ }^{\circledR} 100$ Premix e seu uso é liberado para ser incluído em dietas para ruminantes em crescimento, terminação e vacas lactantes.

A melhoria da eficiência alimentar proporcionada pela monensina é resultante das mudanças na população microbiana do rúmen e, conseqüentemente, no padrão de fermentação dos alimentos. Assim, quando 
a monensina é adicionada à dieta dos ruminantes, atua sobre o crescimento de determinadas bactérias, de modo que os produtos gerados durante o metabolismo das bactérias beneficiadas proporcionam vantagens nutricionais, metabólicas e na performance do animal.

A presença de uma membrana externa, de natureza lipofílica, existente nas bactérias gram-negativas, juntamente com a habilidade dessas bactérias de gerar ATP a partir da fosforilação por transporte de elétrons, originados dgrame reações como do fumarato ao succinato, do crotonil CoA a butiril CoA e do acrilil CoA a propionil CoA, faz com que as bactérias gramnegativas sejam resistentes a ação dos ionóforos (Machado \& Madeira, 1990).

O modelo desenvolvido por Russell \& Strobel (1989) visa explicar os efeitos da utilização do ionóforo monensina sódica sobre o desenvolvimento do Streptococcus bovis, uma bactéria ruminal grampositiva (Figura 1). Quando a monensina liga-se à membrana celular, a primeira reação que ocorre é a rápida saída de $\mathrm{K}^{+}$e uma entrada de $\mathrm{H}^{+}$na célula, provocada pela mudança do gradiente iônico externo. $\mathrm{O} \mathrm{H}^{+}$acumulado no interior da célula ocasiona diminuição do $\mathrm{pH}$. A célula responde a esta queda no $\mathrm{pH}$ exportando $\mathrm{H}^{+}$para fora e permitindo a entrada de $\mathrm{Na}^{+}$para o interior da célula. A segunda reação se caracteriza pelo transporte de $\mathrm{Na}^{+}$para dentro e de $\mathrm{H}^{+}$para fora da célula, embora esta seja menos eficiente que a primeira reação. Outra forma de exportar o $\mathrm{H}^{+}$é por meio da bomba de próton ATPase. Assim, grande parte da energia produzida pela célula é utilizada pelas bombas de $\mathrm{Na}^{+} / \mathrm{K}^{+}$e de próton ATPase, na tentativa de manter o $\mathrm{pH}$ e o balanço iônico celular. Com o passar do tempo, a célula se torna incapaz de continuar metabolizando a glicose, diminuindo a capacidade de crescimento e de reprodução das bactérias, que acabam morrendo ou assumem um nicho microbiano sem expressão ruminal.

Desse modo, como a monensina sódica age selecionando as bactérias gram-negativas (Russell \& Wallace, 1997) a produção de ácidos graxos voláteis é modificada, ocorrendo diminuição da proporção molar dos ácidos acético e butírico (McGuffey et al., 2001), com conseqüente redução das produções dos gases metano - $\mathrm{CH}_{4}$ e carbônico - $\mathrm{CO}_{2}$ (Bagg, 1997), e aumento da proporção de ácido propiônico (Badawy et al., 1996), seguido por elevação das concentrações de propionato hepático e dos níveis de glicose sanguínea (Maas et al., 2001). Outros efeitos benéficos da monensina, em nível ruminal, são o controle do lactato, graças à inibição do Streptococcus bovis - principal bactéria causadora da acidose láctica (Dennis et al., 1981), a elevação do pH ruminal, sobretudo em dietas com alta porcentagem de grãos (Russell, 1996), e a diminuição da concentração de amônia ruminal, em decorrência da menor degradação de peptídeos e aminoácidos no rúmen, que posteriormente são digeridos e absorvidos no intestino delgado (Hegazy \& Elias, 1997). Ressalta-se também que a monensina promove redução da ingestão, seguida por modificações na taxa de passagem do alimento (Machado \& Madeira, 1990), além de melhoria na digestibilidade das dietas (Wedegaertner \& Johnson, 1983).

No Brasil, a partir dos anos 90, o uso de alimentos concentrados na alimentação de bovinos tem crescido rapidamente, impulsionado pela necessidade de aumento na produtividade. Todavia, o uso de alimentos com alta qualidade nutricional não assegura o máximo desempenho animal concomitantemente com a melhor eficiência econômica. Assim, os alimentos concentrados, que constituem a fração mais onerosa da ração, devem ser usados somente para corrigir as deficiências nutritivas dos alimentos volumosos que serão oferecidos aos animais. Segundo Ferreira (1983), a fração nutritiva mais cara dos alimentos concentrados é a proteína; no entanto, ela se destaca pela amplitude de funções que desempenha no organismo animal, participando da formação de tecidos (músculos, cartilagens, unhas, pele e pêlos) e da síntese de glicose, além de exercer as funções hormonal, enzimática, de transporte e de metabolismo de nutrientes.

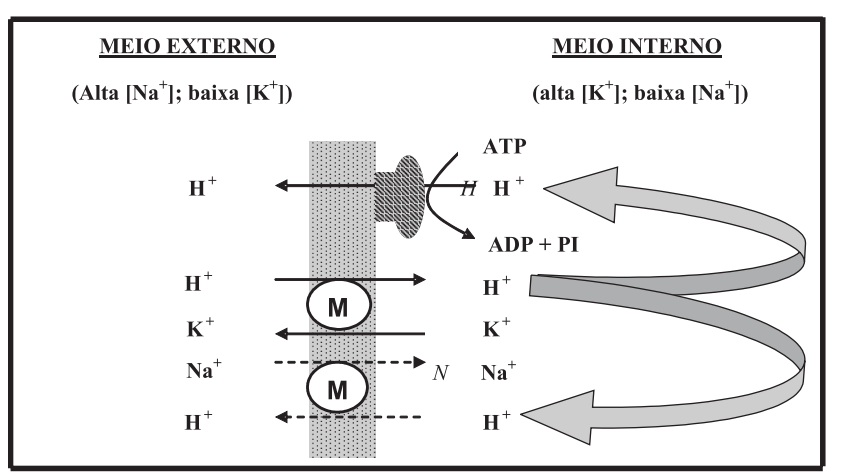

Figura 1- Efeitos hipotéticos da monensina (M) sobre o fluxo de íons em bactérias gram-positivas Streptococcus bovis (Russell \& Strobel,1989).

Figure 1 - Hypothetical effects of monensin (M) on the ions flow in gram-positive bacteria - Streptococcus bovis (Russell \& Strobel,1989). 
Objetivou-se com este experimento verificar a influência da monensina sódica sobre o consumo e a fermentação ruminal em bovinos alimentados com dietas contento dois teores de proteína (baixo e alto).

\section{Material e Métodos}

O experimento foi conduzido no Departamento de Zootecnia e as análises químicas foram realizadas nos Laboratórios de Nutrição Animal, de Microbiologia de Anaeróbios e de Química da Universidade Federal de Viçosa, em Viçosa-MG.

Foram utilizados quatro novilhos holandeses fistulados no rúmen, alimentados com dietas contendo teores baixo e alto de proteína, com e sem monensina, totalizando quatro dietas experimentais; ou seja, foram avaliados quatro tratamentos (dietas), obtidos pela combinação fatorial de dois níveis de proteína (baixo e alto) e dois de monensina (sem e com), com o intuito de se verificar a influência do ionóforo sobre o consumo e a fermentação ruminal. As dietas contendo teores baixo e alto de proteína possuíam, respectivamente, 11,45 e $16,54 \%$ de proteína bruta na matéria seca e eram constituídas por $65 \%$ de feno de capim-braquiária (Brachiaria decumbens) e 35\% de concentrado, sendo o concentrado da dieta com baixo teor protéico à base de milho e uréia e o da dieta com alto teor protéico à base de milho e farelo de soja (Tabela 1). As composições bromatológicas do feno de capim-braquiária e da ração concentrada ofertadas aos animais são apresentadas na Tabela 2.

Foram avaliadas as variáveis consumo de matéria seca, expresso em kg/dia (CMS), em porcentagem do peso vivo (CMSPV) e em função do peso metabólico (CMSPM); pH do líquido ruminal; concentração ruminal de amônia e dos ácidos acético, propiônico e butírico; relação acetato:propionato; atividade específica de produção de amônia (AEPA); e proteína microbiana, em função dos tratamentos (dietas), conforme será explicado adiante (Tabela 3).

Os novilhos, com peso vivo médio de 506,4kg, permaneceram confinados em baias individuais, num galpão de alvenaria com piso de borracha, provida de cocho e bebedouro automático. Antes de se iniciar o experimento, todos os animais foram vermifugados e pesados.

Os alimentos foram fornecidos na forma de ração completa, em quatro refeições diárias às 8, 11, 14 e 17 h, nas proporções de 20, 20, 20 e 40\%, respectivamente, com o escopo de se manter estável a população
Tabela 1 - Composição percentual dos ingredientes e teores de proteína bruta e nutrientes digestíveis totais das dietas com baixo e alto teores protéicos na matéria seca

Table 1 - Composition (\%) of the ingredients, crude protein and total digestible nutrients of diets with low and high protein contents, dry matter basis

\begin{tabular}{|c|c|c|}
\hline \multirow[t]{2}{*}{$\begin{array}{l}\text { Ingrediente }{ }^{1} \\
\text { Ingredient }\end{array}$} & \multicolumn{2}{|c|}{$\begin{array}{l}\text { Teor protéico } \\
\text { Protein content }\end{array}$} \\
\hline & $\begin{array}{c}\text { Baixo } \\
\text { Low }\end{array}$ & $\begin{array}{l}\text { Alto } \\
\text { High }\end{array}$ \\
\hline $\begin{array}{l}\text { Feno de capim-braquiária (\%) } \\
\text { Brachiaria hay (\%) }\end{array}$ & 65,11 & 65,00 \\
\hline $\begin{array}{l}\text { Milho grão (\%) } \\
\text { Corn grain (\%) }\end{array}$ & 33,25 & 14,70 \\
\hline $\begin{array}{l}\text { Uréia (\%) } \\
\text { Urea (\%) }\end{array}$ & 0,91 & - \\
\hline $\begin{array}{l}\text { Sulfato de amônia (\%) } \\
\text { Ammonium sulfate (\%) }\end{array}$ & 0,09 & - \\
\hline $\begin{array}{l}\text { Farelo de soja (\%) } \\
\text { Soybean meal (\%) }\end{array}$ & - & 20,0 \\
\hline $\begin{array}{l}\text { Mistura mineral }(\%)^{2} \\
\text { Mineral mixture }(\%)^{2}\end{array}$ & 0,64 & 0,33 \\
\hline $\begin{array}{l}\text { Total (\%) } \\
\text { Total (\%) }\end{array}$ & 100,00 & 100,00 \\
\hline $\begin{array}{l}\text { Proteína bruta (\% na MS) } \\
\text { Crude protein (\% DM) }\end{array}$ & 11,45 & 16,54 \\
\hline $\begin{array}{l}\text { Nutrientes digestíveis totais } \\
\text { (\% na MS) } \\
\text { Total digestible nutrients (\% DM) }\end{array}$ & 64,26 & 66,26 \\
\hline
\end{tabular}

${ }^{1}$ Foram adicionados $0,33 \mathrm{~g}$ de Rumensin ${ }^{\circledR} / \mathrm{kg}$ de matéria seca oferecida, correspondendo aos tratamentos com $28 \mathrm{mg}$ de monensina/kg de MS consumida.

2 Mistura mineral contendo em cada kg: $25 \mathrm{~g}$ de sulfato de amônio, $75 \mathrm{~g}$ de cloreto de potássio, $425 \mathrm{~g}$ de fosfato bicálcico, $250 \mathrm{~g}$ de calcário calcítico, 209,85 g de sal comum, $12,5 \mathrm{~g}$ de sulfato de zinco, $2,5 \mathrm{~g}$ de sulfato de cobre e $0,15 \mathrm{~g}$ de sulfato de cobalto.

${ }^{1}$ Added $0.33 \mathrm{~g}$ of Rumensin ${ }^{\circledR} / \mathrm{kg}$ of dry matter offered, corresponding to the treatments with $28 \mathrm{mg}$ of monensin/ $\mathrm{kg}$ of DM intake.

${ }^{2}$ Mineral mixture containing in each $\mathrm{kg}: 25 \mathrm{~g}$ of ammonium sulfate, $75 \mathrm{~g}$ of potassium chloride, $425 \mathrm{~g}$ of dicalcium phosphate, $250 \mathrm{~g}$ of limestone, $209.85 \mathrm{~g}$ of salt, $12.5 \mathrm{~g}$ of zinc sulfate, $2.5 \mathrm{~g}$ of copper sulfate and $0.15 \mathrm{~g}$ of cobalt sulfate.

microbiana do rúmen. O nível de Rumensin ${ }^{\circledR}$ (produto comercial contendo $10 \%$ de monensina) incluído diariamente no concentrado foi de $0,33 \mathrm{~g} / \mathrm{kg}$ de matéria seca oferecida, correspondendo aos tratamentos com $28 \mathrm{mg}$ de monensina/kg de matéria seca consumida.

O experimento teve duração de 40 dias, divididos em quatro períodos de 10 dias; os sete primeiros dias foram destinados à adaptação dos animais e da microbiota ruminal à nova alimentação e os três últimos, à determinação do consumo de MS e à coleta do líquido ruminal. O delineamento experimental adotado foi um quadrado latino $4 \times$ 4 - quatro animais e quatro tratamentos (dietas), arranjados em esquema fatorial 2 
Tabela 2 - Composição bromatológica ${ }^{1}$ do feno de capim-braquiária e da ração concentrada ofertados aos animais Table 2 - Chemical composition ${ }^{1}$ of brachiaria hay and concentrate diet fed to animals

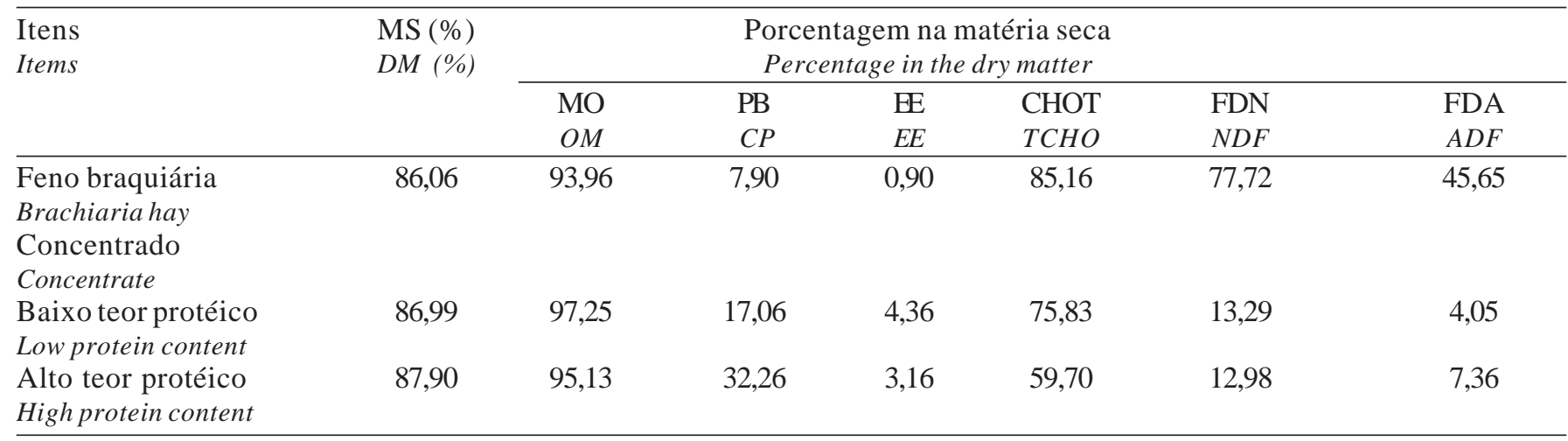

${ }^{1}$ MS (matéria seca); MO (matéria orgânica); PB (proteína bruta); EE (extrato etéreo); CHOT (carboidratos totais); FDN (fibra em detergente neutro); e FDA (fibra em detergente ácido).

${ }^{1}$ DM (dry matter); OM (organic matter); CP (crude protein); EE (ethereal extract); TCHO (totals carbohydrates); NDF (neutral detergent fiber; and ADF (acid detergent fiber).

Tabela 3 - Valores médios e níveis descritivos (valor de P) do teste F da ANOVA para consumo de matéria seca, expresso em kg/dia (CMS), em porcentagem do peso vivo (CMSPV) e em função do peso metabólico (CMSPM), pH, concentração dos ácidos acético, propiônico e butírico, relação acetato:propionato, amônia, atividade específica de produção de amônia (AEPA) e proteína microbiana nas dietas experimentais

Table 3 - Mean values and descriptive levels (value of $P$ ) of $F$ test of ANOVA for dry matter intake, $\mathrm{kg} /$ day (DMI), in percentage of body weight (DMILW) and metabolic weight (DMIMW), $\mathrm{pH}$, concentration of acetic, propionic and butyric acids, acetate:propionate ratio, ammonia, specific activity of ammonia production (SAAP) and microbial protein, regarding the last three days of evaluation, for the experimental diets

\begin{tabular}{|c|c|c|c|c|c|c|c|c|}
\hline \multirow[t]{3}{*}{$\begin{array}{l}\text { Variável } \\
\text { Variable }\end{array}$} & \multicolumn{4}{|c|}{$\begin{array}{l}\text { Teor protéico } \\
\text { Protein content } \\
\end{array}$} & \multirow{3}{*}{ CV (\%) } & \multicolumn{3}{|c|}{$\begin{array}{c}\text { Valor de P } \\
\text { P-value }\end{array}$} \\
\hline & \multicolumn{2}{|c|}{ Baixo(Low) } & \multicolumn{2}{|c|}{ Alto (High) } & & \multirow{2}{*}{$\begin{array}{c}\text { Teor } \\
\text { protéico }(\mathrm{TP}) \\
\text { Protein } \\
\text { content }(P C)\end{array}$} & \multirow{2}{*}{$\begin{array}{c}\text { Monensina } \\
(\mathrm{M}) \\
\text { Monensin } \\
(M)\end{array}$} & \multirow{2}{*}{$\begin{array}{l}\mathrm{TP} * \mathrm{M} \\
P C * M\end{array}$} \\
\hline & $\begin{array}{c}\text { Sem M } \\
\text { Without } \\
\text { monensin }\end{array}$ & $\begin{array}{c}\text { Com M } \\
\text { With } \\
\text { monensin }\end{array}$ & $\begin{array}{l}\text { Sem M } \\
\text { Without } \\
\text { monensin }\end{array}$ & $\begin{array}{l}\text { Com M } \\
\text { With } \\
\text { monensin }\end{array}$ & & & & \\
\hline $\begin{array}{l}\text { CMS - kg/animal/dia } \\
\text { DMI - kg/animal/day }\end{array}$ & 11,73 & 9,08 & 11,47 & 10,25 & 5,03 & 0,137 & 0,0003 & 0,037 \\
\hline $\begin{array}{l}\text { CMSPV - kgMS/100kg PV } \\
D M I L W-\mathrm{kgDM} / 100 \mathrm{~kg} \mathrm{BW}\end{array}$ & 2,33 & 1,80 & 2,27 & 2,02 & 5,07 & 0,168 & 0,0003 & 0,041 \\
\hline $\begin{array}{l}\text { CMSPM- gMS/(kgPV })^{0,75} \\
D M I M W-g D M(\mathrm{~kg} \mathrm{BW})^{0.75}\end{array}$ & 110,11 & 85,20 & 107,59 & 95,91 & 5,07 & 0,157 & 0,0004 & 0,040 \\
\hline $\mathrm{pH}$ & 6,44 & 6,77 & 6,60 & 6,63 & 1,80 & 0,810 & 0,0247 & 0,045 \\
\hline $\begin{array}{l}\text { Ácido acético - } \mathrm{m} \mathrm{mol} / \mathrm{L} \\
\text { Acetic acid - } \mathrm{m} \mathrm{mol} / \mathrm{L}\end{array}$ & 80,24 & 60,33 & 74,56 & 67,13 & 6,38 & 0,814 & 0,0009 & 0,032 \\
\hline $\begin{array}{l}\text { Ácido propiônico - } \mathrm{m} \text { mol/L } \\
\text { Propionic acid - } \mathrm{m} \mathrm{mol} / \mathrm{L}\end{array}$ & 18,60 & 20,87 & 18,56 & 23,42 & 10,52 & 0,285 & 0,0158 & 0,272 \\
\hline $\begin{array}{l}\text { Ácido butírico - m mol/L } \\
\text { Butyric acid - } m \mathrm{~mol} / \mathrm{L}\end{array}$ & 9,16 & 6,18 & 9,98 & 7,91 & 9,43 & 0,017 & 0,0007 & 0,289 \\
\hline $\begin{array}{l}\text { Relação acetato:propionato } \\
\text { Acetate:propionate ratio }\end{array}$ & 4,34 & 2,89 & 4,04 & 2,88 & 5,40 & 0,140 & 0,0001 & 0,180 \\
\hline $\begin{array}{l}\text { Amônia - mg/dL } \\
\text { Ammonia - mg/dL }\end{array}$ & 8,13 & 7,74 & 14,55 & 17,93 & 27,35 & 0,002 & 0,3989 & 0,298 \\
\hline $\begin{array}{l}\text { AEPA - nmol } \mathrm{NH}_{3} / \mathrm{mg} \\
\text { proteína } / \mathrm{min} \\
\text { SAAP - nmol } \mathrm{NH}_{3} / \mathrm{mg} \text { protein } /\end{array}$ & 24,43 & 17,14 & 22,27 & 20,01 & 17,55 & 0,853 & 0,0407 & 0,221 \\
\hline $\begin{array}{l}\text { Proteína microbiana - mg/L } \\
\text { Microbial protein - mg/L }\end{array}$ & $1.595,40$ & $2.579,90$ & $2.156,10$ & $2.313,80$ & 10,00 & 0,222 & 0,0019 & 0,009 \\
\hline
\end{tabular}


x 2, ou seja, dois teores de proteína (baixo e alto) e dois níveis de monensina (sem e com). Os tratamentos foram avaliados por contrastes ortogonais. Quando a interação nível de proteína (P) x monensina (M) foi significativa $(\mathrm{P}<0,05$ na ANOVA), desdobrou-se a ANOVA em $\mathrm{P}+\mathrm{M} / \mathrm{P}$ e depois em $\mathrm{M}+\mathrm{P} / \mathrm{M}$. As médias foram comparadas pelo teste SNK ("Student Newman Keuls”) a 5\% de probabilidade e as análises estatísticas foram realizadas com o auxílio do programa SAS. (1997). Desse modo, a análise estatística dos dados, para cada variável analisada, permitiu inferir sobre os efeitos do nível de proteína na dieta, sobre a eficácia da inclusão de monensina na dieta e se houve interação entre os níveis de proteína e de monensina na dieta.

Tanto os alimentos oferecidos como as sobras foram coletados diariamente, pesados e amostrados. As amostras foram congeladas, formando-se uma amostra composta do período por animal, para análise do teor de MS, segundo metodologia descrita por Silva (1990).

As amostras de líquido ruminal foram coletadas diariamente às $13 \mathrm{~h}$; ou seja, duas horas após o fornecimento da dieta das $11 \mathrm{~h}$. Imediatamente após a coleta, o líquido foi filtrado em quatro camadas de gaze e teve seu $\mathrm{pH}$ determinado com auxílio de um peagâmetro. Em seguida, as amostras do líquido ruminal foram resfriadas com gelo e transportadas para o laboratório, para análises dos teores de amônia e de ácidos graxos voláteis (acético, propiônico e butírico).

A análise de amônia foi feita segundo o método colorimétrico descrito por Chaney \& Marbach (1962) e adaptado ao Laboratório de Microbiologia de Anaeróbios - UFV (Oliveira, 2003). As análises de ácidos graxos voláteis foram realizadas segundo o método descrito por Erwin et al. (1961) e adaptado ao Laboratório de Química - UFV (Oliveira, 2003), emrpegando-se um cromatógrafo a gás.

A determinação da atividade específica de produção de amônia (AEPA) foi realizada no último dia de cada período experimental, calculando-se a quantidade de amônia produzida por mg de proteína microbiana por minuto (Oliveira, 2003). Foram determinados os consumos de matéria seca, expressos em kg/dia, em porcentagem do peso vivo e em função do peso metabólico; o pH ruminal; as concentrações ruminais de amônia e dos ácidos acético, propiônico e butírico; a relação acetato:propionato; a proteína microbiana no líquido ruminal; e a atividade específica de produção de amônia (AEPA).

\section{Resultados e Discussão}

Nas Tabelas 3, 4 e 5 são apresentados os resumos dos resultados das análises estatísticas. Ressalta-se que a Tabela 3 é um guia para as Tabelas 4 e 5, ou seja, na Tabela 3 são descritos os valores médios e os níveis descritivos (valor de P) do teste F da ANOVA para as variáveis: consumo de MS; $\mathrm{pH}$; concentrações ruminais dos ácidos acético, propiônico e butírico e de amônia; relação acetato:propionato; atividade específica de produção de amônia (AEPA); e proteína microbiana, de acordo com cada tratamento. $\mathrm{Na}$ Tabela 3 pode ser observado, a partir dos níveis de significância, se individualmente o teor de proteína (TP) ou a monensina (M) e a interação teor de proteína x monensina (TPxM) influenciaram as variáveis testadas. Na Tabela 4 são reportados os valores médios das variáveis ácidos propiônico e butírico, relação acetato:propionato, amônia e AEPA e apresentadas, de acordo com o teste $\mathrm{F}$, as diferenças estatísticas a 5\%. Todavia, nesse caso, os tratamentos foram agrupados em função do teor protéico e em função da monensina, sem haver, portanto, interferência da interação TPxM. Na Tabela 5 encontram-se os valores médios observados com o desdobramento da interação TPxM, para as variáveis que apresentaram diferenças significativas, ou seja, consumo de MS, pH, ácido acético e proteína microbiana (Tabela 3).

Neste experimento, o consumo de MS, expresso em $\mathrm{kg} / \mathrm{dia}$, $\mathrm{kg}$ de MS/100 kg de peso vivo e g de MS/ (kg de PV $)^{0,75}$, foi reduzido significativamente com a adição de monensina (Tabelas 3 e 5). Para as dietas com monensina, o nível de proteína também influenciou o consumo, que foi maior quando os animais receberam dieta com alto teor protéico (Tabela 5).

Abe et al. (1994), ao ministrarem monensina, em cápsula de liberação controlada, a vacas leiteiras, também verificaram menor ingestão de matéria seca. Também Green et al. (1999), ao fornecerem a vacas leiteiras 0, 8, 16 ou 24 mg monensina/kg MS, observaram que o consumo antes do parto foi reduzido nas vacas que receberam $24 \mathrm{mg}$. Entretanto, após o parto (até aproximadamente a 9a semana), o consumo não foi influenciado pela monensina, havendo nova redução de consumo no período restante da lactação. Diminuições no consumo de matéria seca, acarretadas pela inclusão de monensina, também foram relatadas por Restle et al. (2001) e Maas et al. (2001), que 
Tabela 4 - Concentração dos ácidos propiônico e butírico, relação acetato:propionato, amônia e atividade específica de produção de amônia (AEPA), de acordo com teor protéico e monensina

Table 4 - Concentration of propionic and butyric acids, acetate:propionate ratio, ammonia, and specific activity of ammonia production (SAAP), according to protein content and monensin

\begin{tabular}{|c|c|c|c|c|}
\hline \multirow[t]{2}{*}{$\begin{array}{l}\text { Variável } \\
\text { Variable }\end{array}$} & \multicolumn{2}{|c|}{$\begin{array}{l}\text { Teor protéico } \\
\text { Protein content }\end{array}$} & \multicolumn{2}{|c|}{$\begin{array}{l}\text { Monensina } \\
\text { Monensin }\end{array}$} \\
\hline & $\begin{array}{l}\text { Baixo } \\
\text { Low }\end{array}$ & $\begin{array}{l}\text { Alto } \\
\text { High }\end{array}$ & $\begin{array}{c}\text { Sem } \\
\text { Without }\end{array}$ & $\begin{array}{l}\text { Com } \\
\text { With }\end{array}$ \\
\hline $\begin{array}{l}\text { Ácido propiônico - m mol/L } \\
\text { Propionic acid - } m \mathrm{~mol} / \mathrm{L}\end{array}$ & 19,73а & $20,99 a$ & $18,58 b$ & $22,15 a$ \\
\hline $\begin{array}{l}\text { Ácido butírico - } \mathrm{m} \mathrm{mol} / \mathrm{L} \\
\text { Butyric acid - } m \mathrm{~mol} / \mathrm{L}\end{array}$ & $7,67 \mathrm{~b}$ & $8,94 a$ & $9,57 a$ & $7,04 b$ \\
\hline $\begin{array}{l}\text { Relação Acetato:Propionato } \\
\text { Acetate:Propionate ratio }\end{array}$ & $3,62 \mathrm{a}$ & $3,46 a$ & $4,19 a$ & $2,89 b$ \\
\hline $\begin{array}{l}\text { Amônia - mg/dL } \\
\text { Ammonia - mg/dL }\end{array}$ & 7,93b & $16,24 a$ & $11,34 a$ & 12,83a \\
\hline $\begin{array}{l}\text { AEPA - nmol } \mathrm{NH}_{3} / \mathrm{mg} \text { proteína/min } \\
\text { SAAP - nmol } \mathrm{NH}_{3} / \mathrm{mg} \text { protein } / \mathrm{min}\end{array}$ & 20,78a & $21,14 a$ & $23,35 a$ & $18,57 b$ \\
\hline $\begin{array}{l}\text { Proteína microbiana - mg/L } \\
\text { Microbial protein - mg/L }\end{array}$ & $2.087,65 a$ & $2.234,95 a$ & $1.875,75 b$ & $2.446,85 a$ \\
\hline
\end{tabular}

Médias com letras diferentes na mesma linha, dentro de cada fator, indicam diferenças significativas a $5 \%$ de acordo com o teste $\mathrm{F}$. Averages with different letters in a row, within each factor, indicate significant differences at $5 \%$ level according to $F$ test.

Tabela 5 - Valores médios observados com o desdobramento da interação teor protéico x monensina, para consumo de matéria seca, expresso em kg/dia (CMS), em porcentagem do peso vivo (CMSPV) e em função do peso metabólico (CMSPM), pH, concentração do ácido acético e proteína microbiana, de acordo com o teor protéico e a monensina

Table 5 - Average values observed with the unfolding of protein content $x$ monensin interaction, for dry matter intake, expressed as $\mathrm{kg} /$ day (DMI), as percentage of body weight (DMIBW) and as metabolic weight (DMIMW), pH, acetic concentration and microbial protein, according to protein content and monensin

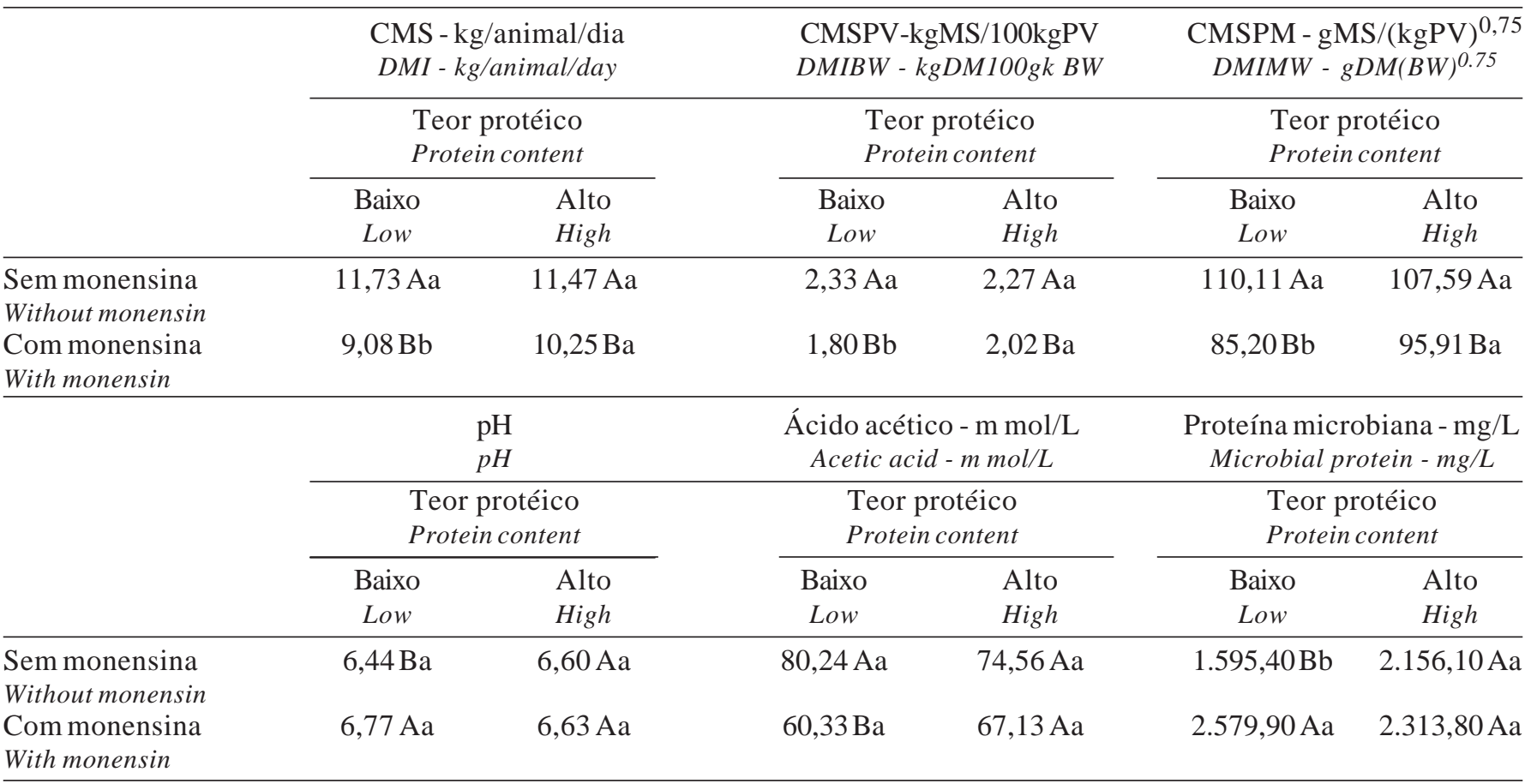

Médias com letras maiúsculas diferentes na mesma coluna, dentro de cada fator, indicam diferenças significavas a 5\%, pelo teste SNK, para os tratamentos sem e com monensina, respectivamente.

Médias com letras minúsculas diferentes na mesma linha, dentro de cada fator, indicam diferenças significavas a $5 \%$, pelo teste SNK, para os tratamentos com baixo e alto teor protéico, respectivamente.

Averages with different capital letters within a column, within each factor, indicate significant differences at $5 \%$ level by SNK test, for the treatments without and with monensin, respectively.

Averages with different small letters in a row, within each factor, indicate significant differences at $5 \%$ level by SNK test, for the treatments with low and high protein content, respectively. 
trabalharam com novilhas e vacas de corte mantidas em regime de confinamento e carneiros alimentados com capim fresco colhido na primavera e no outono, respectivamente. Todavia, Ruiz et al. (2001) e Oliveira et al. (2002a) não verificaram diferenças no consumo de matéria seca, ao fornecerem monensina a vacas alimentadas com dietas à base de forragem fresca e a novilhas holandesas, mantidas confinadas, recebendo $67,16 \%$ de silagem de milho e cana-de-açúcar (1:1 na MS) e $32,84 \%$ de concentrado, respectivamente.

$\mathrm{O}$ pH ruminal é influenciado principalmente pela produção de saliva. Por isso, animais alimentados com dietas contendo elevada porcentagem de alimentos volumosos normalmente apresentam $\mathrm{pH}$ ruminal sempre próximo à neutralidade, graças ao maior estímulo de produção de saliva, durante os processos de ingestão e regurgitação dos alimentos. Nestes casos, os efeitos da monensina sobre o $\mathrm{pH}$ são pouco expressivos. Todavia, animais recebendo dietas com alta porcentagem de grãos, possuem naturalmente menor secreção de saliva, o que acarreta declínio do $\mathrm{pH}$, seguido por aumento do crescimento das bactérias Streptococcus bovis, com conseqüente elevação da produção de lactato, acentuada queda no $\mathrm{pH}$ e sintomas de acidose. Nesses casos, Russell (1996) observou que a inclusão de monensina é altamente benéfica, por causar inibição do desenvolvimento dessas bactérias e elevação do pH ruminal.

Neste experimento, com a inclusão da monensina, duas horas após a alimentação, verificou-se significativo aumento do pH ruminal nos animais alimentados com a dieta contendo baixo teor protéico, enquanto, nos animais alimentados com dietas contendo alto teor protéico, o aumento médio no $\mathrm{pH}$ não foi estatisticamente significativo (Tabela 5). Entre os tratamentos com baixo e alto teores protéicos, não foram verificadas diferenças significativas na variável pH (Tabelas 3 e 5). Com o intuito de avaliar os efeitos da amonização do feno de capim-bermuda em relação à suplementação com uréia, sem ou com a adição de monensina, fornecido a novilhos holandeses, Vagnoni et al. (1995) também observaram que a monensina promovia aumento significativo do $\mathrm{pH}$ ruminal, independentemente da dieta fornecida aos animais. Elevações do $\mathrm{pH}$ ruminal, após a administração de monensina, também foram mencionadas por Garrett et al. (1989) e Ivan et al. (1992), em novilhos de origem leiteira e carneiros faunados e defaunados, respectivamente.

Ahuja et al. (1990), estudando bezerros-búfalos submetidos à acidose láctica, induzida com melaço administrado oralmente, também verificaram que a monensina promovia aumento no $\mathrm{pH}$ ruminal, além de queda significativa do conteúdo de ácido láctico no líquido ruminal. Reduções dos sintomas de acidose, com elevação do pH ruminal e diminuição das flutuações diárias do $\mathrm{pH}$, de animais recebendo dietas com alta porcentagem de grãos associadas a monensina também foram relatadas por Lee et al. (1990) e Zhou \& Clark (1999), ao fornecerem 80 e 92,5\% de concentrado, respectivamente, a cabritos nativos da Coréia e a novilhos fistulados no rúmen, respectivamente. No entanto, Towne et al. (1990) ao coletarem líquido ruminal, com auxílio de sonda estomacal, de novilhas confinadas, alimentadas com dietas com $85 \%$ de concentrado e suplementadas com monensina, não verificaram alterações no pH ruminal ou na concentração de ácido láctico. Analogamente, Harmon et al. (1993), Haimoud et al. (1995), Hegazy \& Elias (1997) e Garcia et al. (2000) não observaram nenhuma mudança no pH ruminal, ao fornecerem monensina a novilhos holandeses, a vacas lactantes fistuladas no rúmen, duodeno e íleo, a cordeiros da raça Barki e a carneiros da raça Suffolk fistulados no rúmen, respectivamente.

Em condições de pastejo, utilizando novilhos fistulados no rúmen, Davenport et al. (1989), Ward et al. (1990), Fredrickson et al. (1993) e Andrae et al. (1995) também não verificaram alterações significativas no $\mathrm{pH}$ ruminal.

Aproximadamente 90\% da matéria orgânica digerível consumida pelos ruminantes é fermentada no rúmen-retículo. Os principais produtos desta fermentação são os ácidos graxos voláteis (acético, propiônico e butírico, principalmente), que são absorvidos pelo epitélio ruminal, os gases metano e dióxido de carbono, que são eliminados via eructação, e as células microbianas que, ao serem digeridas no intestino delgado, liberam aminoácidos e ácidos graxos (Hungate, 1966). Segundo Bagg (1997), os ácidos graxos voláteis representam a principal fonte energética dos ruminantes, uma vez que durante a formação dos ácidos acético e butírico, ocorre a produção de dióxido de carbono e metano, ocasionando perda de energia; no entanto, na formação doácido propiônico isto não ocorre. Como os ionóforos atuam aumentando a porcentagem de ácido propiônico e diminuindo a dos ácidos acético e butírico, conseqüentemente, há maior eficiência no processo fermentativo e menor perda energética.

Neste experimento (Tabelas 3 e 4), observou-se que o fornecimento de monensina aos novilhos também 
promoveu aumento da concentração do ácido propiônico e redução do ácido butírico e da relação acetato:propionato no rúmen. A concentração do ácido acético também foi reduzida (Tabelas 3 e 5), entretanto, significativamente, somente nos animais que receberam dieta com baixo teor protéico. Zinn \& Borques (1993), ao fornecerem monensina (33 mg/kg) a novilhos holandeses, alimentados com dietas à base de milho floculado (75\%) e forragem (12\%), também verificaram diminuições na concentração ruminal dos ácidos acético $(5,3 \%)$ e butírico $(29,4 \%, \mathrm{P}<0,05)$ e aumento do ácido propiônico (16,3\%, P<0,10). De modo semelhante, Andrae et al. (1995) e Paisley \& Horn (1998), ao ministrarem monensina a novilhos fistulados no rúmen, mantidos em pastagem de trigo, também observaram aumento do ácido propiônico e menor relação acetato:propionato. Da mesma forma, Baran (1988) e Gado (1997), a fornecerem monensina a carneiros e cabritos, respectivamente, observaram diminuições nas concentrações ruminais dos ácidos acético e butírico e aumento na concentração de ácido propiônico. Resultados semelhantes também foram relatados por Ahuja et al. (1990), Puri et al. (1994) e Badawy et al. (1996), em búfalos; por Kalachnyuk et al. (1990), Podsednicek \& Marounek (1991) e Singh \& Mohini (1999), em bezerros; e por Galyean \& Owens (1988), Schuler (1988), Granzin \& Dryden (1999) e Ruiz et al. (2001), em vacas leiteiras. Davenport et al. (1989), Ward et al. (1990) e Branine \& Galyean (1990), por sua vez, não verificaram alterações significativas nas concentrações dos ácidos graxos voláteis, ao fornecerem monensina a novilhos fistulados no rúmen e mantidos em regime de pastejo. Todavia, Mbanzamihigo et al. (1996), ao trabalharem com carneiros fistulados no rúmen e ceco, observaram que, além das alterações ruminais (maior concentração de ácido propiônico e menores teores dos ácidos acético e butírico), a monensina também foi efetiva no funcionamento do ceco, ocasionando as mesmas alterações. Corroborando, Marounek et al. (1990) também verificaram in vitro os efeitos da monensina nos conteúdos de ceco e cólon de novilhos e vacas, observando-se, nesse caso, aumento do ácido propiônico e declínio do ácido butírico, permanecendo o ácido acético inalterado.

O requerimento protéico dos ruminantes, para sua manutenção e produção, é suprido pela proteína metabolizável, que é o somatório dos aminoácidos absorvidos no intestino delgado, provenientes da digestão microbiana e dos alimentos que escapam da fermentação ruminal (Chalupa, 1980). Portanto, quanto maior a produção microbiana menor será a quantidade de fontes protéicas não degradáveis no rúmen necessária para atender o requerimento protéico do animal. De acordo com o AFRC (1993), a máxima síntese microbiana ocorre quando há elevado e adequado ajuste da energia fermentescível, obtida com a fermentação de carboidratos (amido, celulose etc.) no rúmen e com o nitrogênio na forma de amônia, resultante tanto da fermentação da proteína alimentar verdadeira como do nitrogênio não-protéico, na forma de uréia. Todavia, quando há excesso de fermentação de carboidratos, desequilibrando essa relação, ocorre acúmulo de energia fermentescível, que é perdida principalmente na forma de metano, pela eructação. Da mesma maneira, se a hidrólise das proteínas alimentares, que liberam peptídeos, aminoácidos e amônia, ultrapassar a capacidade de assimilação de nitrogênio pelos microrganismos, ocorre acúmulo de amônia no líquido ruminal. Essa amônia em excesso será absorvida pelo epitélio ruminal, metabolizada no fígado e convertida em uréia, podendo ser reciclada pela saliva ou excretada pela urina.

A intensidade da hidrólise depende da solubilidade e da característica estrutural da proteína, além do tipo de processamento (físico ou químico) a que o alimento é submetido e do nível de consumo do animal, que influencia a velocidade de passagem e, conseqüentemente, o tempo de permanência do alimento no rúmen. Segundo Yang \& Russell (1993), uma forma de se reduzir a fermentação de proteínas alimentares, ou seja, de diminuir a concentração de amônia ruminal, é o controle de bactérias proteolíticas, que pode ser alcançado com a adição da monensina sódica. Porém, Lana et al. (1997) advertem que a maior eficiência da monensina em dietas com alto teor protéico é obtida quando se aumenta a quantidade de monensina na dieta dos animais. A utilização deste ionóforo, além de diminuir as perdas de nitrogênio no rúmen, também eleva a quantidade de aminoácidos de origem alimentar que chegam ao intestino delgado, aumentando, assim, o aporte de aminoácidos que serão utilizados para atender o requerimento protéico do animal (Russell \& Strobel, 1989).

Neste experimento, as dietas com alto teor protéico estimularam a produção de amônia ruminal (Tabela 4). Todavia, a inclusão de monensina não promoveu alterações significativas (Tabelas 3 e 4) na concentração de amônia ruminal, observando-se, no entanto, 
uma diminuição não-significativa da concentração de amônia nos novilhos alimentados com a dieta contendo baixo teor protéico mais monensina (Tabela 3).

Lee et al. (1990), ao fornecerem a cabritos nativos da Coréia dietas contendo $80 \%$ de concentrado com $20 \%$ de feno de capim triturado e monensina (0, 22 ou $33 \mathrm{mg} / \mathrm{kg})$, também não verificaram mudanças na concentração de amônia ruminal, ou nos níveis de amônia e uréia plasmática. De maneira semelhante, Davenport et al. (1989), Ward et al. (1990) e Fredrickson et al. (1993), estudando novilhos fistulados no rúmen em regime de pastejo, também não verificaram reduções significativas da amônia ruminal com a inclusão de monensina. Entretanto, diminuições da concentração de amônia foram verificadas por Ruiz et al. (2001), ao fornecerem monensina (350 mg/dia) a vacas holandesas lactantes, alimentadas com forragem fresca. Analogamente, Plaizier et al. (2000) também observaram, em vacas leiteiras, que o fornecimento de monensina em cápsula de liberação controlada promovia queda na concentração de amônia ruminal de 5,4 para 3,2 mg/dL no pré-parto e de 6,0 para 4,9 mg/dL, no pós-parto. Reduções significativas da amônia ruminal, após a inclusão de monensina, também foram relatadas por Yang \& Russell (1993), Hegazy \& Elias (1997) e Rogers et al. (1997). Mbanzamihigo et al. (1996), utilizando carneiros fistulados no rúmen e ceco, alimentados com dietas com alta porcentagem de grãos, verificaram que, além da redução da concentração de amônia ruminal, a monensina também promoveu mudança semelhante no modo de fermentação do trato gastrintestinal inferior.

Os animais que receberam dieta com alto teor protéico mais monensina apresentaram aumento numérico não-significativo, na concentração de amônia ruminal (Tabela 3), o que, teoricamente, não deveria ter ocorrido, uma vez que a inclusão de ionóforo normalmente promove o controle dos microrganismos proteolíticos. Todavia, Oliveira et al. (2002b), ao fornecerem a novilhas leiteiras dietas com $15,5 \%$ de proteína bruta, associadas a diferentes níveis de monensina, apesar de não-significativo, também verificaram, na coleta de líquido ruminal feita duas horas após a alimentação, aumento da concentração de amônia ruminal, nos animais que receberam $28 \mathrm{mg}$ de monensina/kg MS ingerida. Da mesma forma, Mbanzamihigo et al. (1995), ao conduzirem um experimento com carneiros fistulados, alimentados com $300 \mathrm{~g}$ de feno e $300 \mathrm{~g}$ de concentrado, também obser- varam que a concentração de amônia ruminal foi estimulada pela administração de monensina (30 mg/ dia durante 21 dias e seguidos por 28 dias com $60 \mathrm{mg} /$ dia). Branine \& Galyean (1990) e Lana \& Russell (1997) também verificaram aumento da amônia no líquido ruminal de novilhos e vacas fistulados no rúmen, respectivamente, recebendo, além de monensina, pastagem de trigo mais $0,5 \mathrm{~kg} / \mathrm{dia}$ de sorgo floculado e feno de alfafa, respectivamente.

A atividade específica de produção de amônia (AEPA) é uma técnica in vitro utilizada para corroborar a confiabilidade em se quantificar a síntese de amônia pelas bactérias ruminais, obtida no método in vivo. Com o uso dessa técnica, tem-se noção da população de microrganismos fermentadores de aminoácidos preponderantes no rúmen, em função da dieta fornecida aos animais. Inicialmente, acreditavase que ionóforos, como a monensina sódica, inibiam o desenvolvimento somente das bactérias utilizadoras de aminoácidos como fonte exclusiva de energia e nitrogênio. Todavia, Russell (1996) verificou que essas bactérias foram todas resistentes à monensina e significativamente menos produtoras de amônia que as de três grupos (estirpes C, F e SR), sensíveis à monensina e com especificidade muito alta para a produção de amônia. Análises posteriores indicaram que os principais microrganismos de cada estirpe eram o Peptostreptococus anaerobius, Clostridium aminophilum e Clostridium sticklandii para os grupos C, F e SR, respectivamente.

Neste experimento, pela análise da AEPA, verifica-se que ocorreu uma redução significativa na produção de amônia, com a incubação do líquido ruminal dos animais que receberam monensina (Tabelas 3 e 4), comprovando-se, assim, a eficácia desse ionóforo no controle das bactérias proteolíticas e desaminadoras de aminoácidos. Estudando vacas holandesas nãolactantes, alimentadas com feno de capim-timóteo, farelo de soja (1 ou $2 \mathrm{~kg} /$ dia) mais monensina, Yang \& Russell (1993) também registraram diminuição na amônia e AEPA em ambos os níveis de farelo de soja. De modo semelhante, Cunha (1999) também constatou redução da AEPA quando incubou líquido ruminal, com fubá de milho ou farelo de soja ou de trigo mais monensina. Este autor também reportou correlação entre o pH do meio e a concentração de amônia, de modo que, quanto mais baixo o $\mathrm{pH}$, menor foi a produção de amônia, ocorrendo, portanto, maior eficácia da monensina em meios com $\mathrm{pH}$ mais elevado. 
Verificou-se que houve aumento significativo da proteína microbiana no líquido ruminal dos animais alimentados com a dieta contendo baixo teor protéico mais monensina, aumento que também foi verificado numericamente nos animais que receberam dieta com alto teor protéico. Jalc et al. (1992, 1993) e Jalc \& Laukova (2002), utilizando a técnica de simulação ruminal (Rusitec), também verificaram que a eficiência de síntese de massa microbiana foi aumentada com a adição de monensina. Analogamente, Lee et al. (1990) também observaram, em cabritos nativos da Coréia, alimentados com dietas contendo $80 \%$ de concentrado e $20 \%$ de feno triturado, que a monensina promoveu um aumento $(\mathrm{P}<0,05)$ na concentração de proteína microbiana. Yang \& Russell (1993) verificaram que a monensina acarretou diminuição de, aproximadamente, 10 vezes, das bactérias que podem utilizar peptídeos e aminoácidos, mas não carboidratos, como fonte de energia para crescimento. Desse modo, a monensina inibiu a atividade das bactérias fermentadoras de aminoácidos, entre outras, e, conseqüentemente, a desaminação e o nível de amônia ruminal, havendo, no entanto, aumento significativo da concentração de proteína bacteriana no fluido ruminal, aumentando o suprimento de aminoácidos disponíveis para o animal.

Por outro lado, Barbosa (2000) não verificou alterações na proteína microbiana, ao incubar in vitro glúten de milho, uréia ou farelo de soja com monensina. Da mesma forma, Haimoud et al. $(1995,1996)$ não registraram alterações na eficiência de síntese de proteína bacteriana no fluido ruminal e na passagem de nitrogênio bacteriano para o intestino delgado, em vacas leiteiras fistuladas no rúmen, duodeno e íleo, recebendo monensina (33 mg/kg). No entanto, foi notificada menor fermentação do nitrogênio dietético no rúmen, com conseqüente aumento de aminoácidos de origem alimentar no intestino delgado. Zinn et al. (1994) constataram que, quando a monensina foi fornecida a bovinos confinados, havia diminuição $(14,5 \%, \mathrm{P}<0,10)$ na passagem de nitrogênio microbiano para o intestino delgado. De modo semelhante, Ahn et al. (1994) também observaram in vitro que a monensina promovia inibição da taxa de crescimento e do rendimento de nitrogênio microbiano.

\section{Conclusões}

A dieta com alto teor protéico promoveu aumento na concentração ruminal de ácido butírico e de amônia.

O consumo de matéria seca dos animais alimentados com dieta contendo alto teor protéico mais monensina foi maior que daqueles que receberam dieta com baixo teor protéico mais monensina.

O fornecimento de monensina sódica a novilhos holandeses diminuiu o consumo de matéria seca e promoveu mudança nos produtos da fermentação ruminal, o que possivelmente está relacionado à alteração na população microbiana.

\section{Literatura Citada}

AGRICULTURAL AND FOOD RESEARCH COUNCIL AFRC. Energy and protein requirements of ruminants. An advisory manual prepared by the AFRC. Technical Committee on Responses to Nutrients. CAB International, 1993. p.159.

ABE, N.; LEAN, I.J.; RABIEE, A. et al. Effects of sodium monensin on reproductive performance of dairy cattle. II. Effects on metabolites in plasma, resumption of ovarian cyclicity and oestrus in lactating cows. Australian Veterinary Journal, v.71, n.9, p.277-282, 1994.

AHN, J.J.; KAWASHIMA, Y.; INAMOTO, T. et al. Effects of antimicrobial feed additives on ruminal bacteria in vitro. Sustainable animal production and the environment. In: AAAP ANIMAL SCIENCE CONGRESS, 7., 1994, Bali. Proceedings... Bali: 1994. v.3, p.45-46.

AHUJA, A.K.; RANDHAWA, S.S.; RATHOR, S.S. Effect of monensin in ameliorating subacute lactic acidosis in buffalo calves. Acta Veterinaria Brno, v.59, n.3-4, p.171-178, 1990.

ANDRAE, J.G.; HORN, G.W.; BUCHANAN, D.S. et al. Effect of salt intake in a monensin-containing energy supplement on rumen fermentation of steers grazing wheat pasture. Animal Science Research Report Agricultural Experiment Station. Oklahoma: Oklahoma State University, 1995. p.145-150.

BADAWY, S.A.; YOUNIS, M.; SHALASH, M.R. et al. Monensin effects on rumen metabolic profile, methane production and protozoal population in buffalo-heifers. Egyptian Journal of Veterinary Science, v.30, p.49-56, 1996.

BAGG, R. Mode of action of ionophores in lactating dairy cattle. Usefulness of ionophores in lactating dairy cattle. Guelph: Ontario Veterinary College, 1997. p.13-21.

BARAN, M. Rumen fermentation in wethers fed on all-roughage, high-roughage or concentrate diet with monensin. Zivocisna Vyroba, v.33, n.7, p.599-608, 1988.

BARBOSA, N.G.S. Fermentação da proteína dos alimentos por microrganismos ruminais in vivo e in vitro em função da acidez, fontes de proteína e ionóforos. Viçosa, MG: Universidade Federal de Viçosa, 2000. 76p. Dissertação (Mestrado em Zootecnia) - Universidade Federal de Viçosa, 2000. 
BRANINE, M.E.; GALYEAN, M.L. Influence of grain and monensin supplementation on ruminal fermentation, intake, digesta kinetics and incidence and severity of frothy bloat in steers grazing winter wheat pasture. Journal of Animal Science, v.68, n.4, p.1139-1150, 1990.

CHALUPA, W. Methods for estimating protein requirements and feed protein values for ruminants. Feedstuffs, p.18-20, 1980.

CHANEY, A.L.; MARBACH, E.P. Modified reagents for determination of urea and ammonia. Clinical Chemistry, v.8, p.130-132, 1962.

CUNHA, L.T. Efeito da acidez e de ionóforos na degradação de proteínas por microrganismos ruminais. Viçosa, MG: Universidade Federal de Viçosa, 1999. p.68. Dissertação (Mestrado em Zootecnia) - Universidade Federal de Viçosa, 1999.

DAVENPORT, R.W.; GALYEAN, M.L.; BRANINE, M.E. et al. Effects of a monensin ruminal delivery device on daily gain, forage intake and ruminal fermentation of steers grazing irrigated winter wheat pasture. Journal of Animal Science, v.67, n.8, p.2129-2139, 1989.

DENNIS, S.M.; NAGARAJA, T.G.; BARTLEY, E.E. Effect of lasalocid or monensin on lactate-producing or using rumen bacteria. Journal of Animal Science, v.52, p.418-426, 1981.

ERWIN, E.S.; MARCO, G.J.; EMERY, E.M. Volatile fatty acid analyses of blood and rumen fluid by gas chromatography. Journal of Dairy Science, v.44, n.9, p.1768-1771, 1961.

FERREIRA, J.J. Proteína e concentrados protéicos na alimentação de ruminantes. Informe Agropecuário, v.9, n.108, p.43-48, 1983.

FREDRICKSON, E.L.; GALYEAN, M.L.; BRANINE, M.E. et al. Influence of ruminally dispensed monensin and forage maturity on intake and digestion. Journal of Range Management, v.46, n.3, p.214-220, 1993.

GADO, H. Nutrients utilization and growth performance of Baladi goats kids fed monensin sodium supplemented ration. Egyptian Journal of Nutrition and Feeds, No. Nov Special, p.91-98, 1997.

GALYEAN, M.L.; OWENS, F.N. Effects of monensin on growth, reproduction, and lactation in ruminants. ISI Atlas of Science, Animal and Plant Sciences, v.1, n.1, p.71-75, 1988.

GARCIA, C.C.G.; MENDOZA, M.G.D.; GONZALEZ, M.S. et al. Effect of a yeast culture (Saccharomyces cerevisiae) and monensin on ruminal fermentation and digestion in sheep. Animal Feed Science and Technology, v.83, n.2, p.165$170,2000$.

GARRETT, J.E.; GUESSOUS, F.; EDDEBBARH, A. Utilization of sugar beet molasses and monensin for finishing dairy bullocks. Animal Feed Science and Technology, v.25, n.1-2, p.11-21, 1989.

GRANZIN, B.C.; DRYDEN, G.McL. The effects of monensin on milk production and levels of metabolites in blood and rumen fluid of Holstein-Friesian cows in early lactation. Australian Journal of Experimental Agriculture, v.39, n.8, p.933-940, 1999.

GREEN, H.B.; SYMANOWSKI, J.T.; WAGNER, J.R. et al. Effect of monensin on milk production parameters, feed intake, body weight, body condition, and efficiency of milk production when fed to Holsteins. In: ANNUAL CONFERENCE AMERICAN ASSOCIATION OF BOVINE PRACTITIONERS, 32., 1999, Nashville. Proceedings... Nashville: American Association of Bovine Practitioners, 1999. p.236-237.
HAIMOUD, A.D.; BAYOURTHE, C.; MONCOULON, R. et al. Avoparcin and monensin effects on digestive function in cows fed a high forage diet. Journal of the Science of Food and Agriculture, v.70, n.2, p.181-189, 1996.

HAIMOUD, A.D; VERNAY, M.; BAYOURTHE, C. et al. Avoparcin and monensin effects on the digestion of nutrients in dairy cows fed a mixed diet. Canadian Journal of Animal Science, v.75, n.3, p.379-385, 1995.

HANEY, Jr. M.E.; HOEHN, M.M. Monensin, a new biologically active compound. I. Discovery and isolation. Antimicrobial Agents Chemother, p.349, 1967.

HARMON, D.L.; KREIKEMEIER, K.K.; GROSS, K.L. Influence of addition of monensin to an alfalfa hay diet on net portal and hepatic nutrient flux in steers. Journal of Animal Science, v.71, n.1, p.218-225, 1993.

HEGAZY, M.A.; ELIAS, A.N. Influence of dietary monensin and lasalocid on age and weight of Barki ram- and ewe-lambs at puberty. Assiut Veterinary Medical Journal, v.37, n.74, p.1-15, 1997.

HUNGATE, R.E. The rumen and its microbes. New York: Academic Press, 1966. p.533.

IVAN, M.; DAYRELL, M.S.; HIDIROGLOU, M. Effects of bentonite and monensin on selected elements in the stomach and liver of fauna-free and faunated sheep. Journal of Dairy Science, v.75, n.1, p.201-208, 1992.

JALC, D.; BARAN, M.; PETKOV, A.I. et al. The effects of monensin (USA, CSFR, Bulgaria) on the fermentation of feed rations in a artificial rumen (Rusitec). Veterinarni Medicina, v.37, n.1, p.11-19, 1992.

JALC, D.; BARAN, M.; VENDRAK, T. et al. Effect of monensin on fermentation of hay and wheat bran investigated by the rumen simulation technique (Rusitec). 2. End-products of fermentation and protein synthesis. Archives of Animal Nutrition, v.42, n.2, p.153-158, 1993.

JALC, D.; LAUKOVA, A. Effect of nisin and monensin on rumen fermentation in artificial rumen. Berliner und Munchener Tierarztliche Wochenschrift, v.115, n.1-2, p.6-10, 2002.

KALACHNYUK, G.I.; MAROUNEK, M.; SHIMUNEK, I. et al. Effect of ionophore on volatile fatty acid production in the rumen. Sel'skokhozyaistvennaya Biologiya, n.2, p.93-98, 1990.

LANA, R.P.; FOX, D.G.; RUSSELL, J.B. et al. Influence of monensin on Holstein steers fed high-concentrate diets containing soybean meal or urea. Journal of Animal Science, v.75, p.2571-2579, 1997.

LANA, R.P.; RUSSELL, J.B. Effect of forage quality and monensin on the ruminal fermentation of fistulated cows fed continuously at a constant intake. Dairy Forage Research Center, Research Summaries, p.85-87, 1997.

LEE, S.K.; LEE, B.D.; JUNG, K.K. et al. Effect of feeding monensin on the feed intake, nutrient utilization and ruminal fermentation of Korean native goat. Korean Journal of Animal Sciences, v.32, n.2, p.74-82, 1990.

LOWRY, O.H.; ROSEBROUGH, N.J.; FARR, A.L. et al. Protein measurement with the Folin phenol reagent. Journal Biological Chemistry, v.193, p.265-275, 1951.

MAAS, J.A.; WILSON, G.F.; McCUTCHEON, S.N. et al. The effect of season and monensin sodium on the digestive characteristics of autumn and spring pasture fed to sheep. Journal of Animal Science, v.79, n.4, p.1052-1058, 2001.

MACHADO, P.F.; MADEIRA, H.M.F. Manipulação de nutrientes em nível de rúmen - efeitos do uso de ionóforos. In: REUNIÃO ANUAL DA SOCIEDADE BRASILEIRA DE 
Zootecnia, 1990, Piracicaba. Anais... Piracicaba: Fundação de Estudos Agrários Luiz de Queiroz, 1990. p.79-96.

MAROUNEK, M.; PETR, O.; MACHANOVA, L. Effect of monensin on in vitro fermentation of maize starch by hindgut contents of cattle. Journal of Agricultural Science, v.115, n.3, p.389-392, 1990.

MBANZAMIHIGO, L.; Van NEVEL, C.J.; DEMEYER, D.I. Adaptation of rumen fermentation to monensin administration. Reproduction Nutrition Development, v.35, n.4, p.353-365, 1995.

MBANZAMIHIGO, L.; Van NEVEL, C.J.; DEMEYER, D.I. Lasting effects of monensin on rumen and caecal fermentation in sheep fed a high grain diet. Animal Feed Science and Technology, v.62, n.2-4, p.215-228, 1996.

McGUFFEY, R.K.; RICHARDSON, L.F.; WILKINSON, J.I.D. Ionophores for dairy cattle: current status and future outlook. Journal of Dairy Science, v.84, Supplement, p.194-203, 2001.

OLIVEIRA, M.V.M.; LANA, R.P.; CAMPOS, J.M.S. et al. Desempenho de novilhas leiteiras sob dietas com diferentes níveis de monensina. REUNIÃO ANUAL DA SOCIEDADE BRASILEIRA DE ZOOTECNIA, 39., 2002, Recife. Anais... Recife, 2002a, CD-ROM

OLIVEIRA, M.V.M.; LANA, R.P.; VALADARES, R.F.D. et al. Parâmetros ruminais e glicose sanguínea em novilhas leiteiras sob dietas com diferentes níveis de monensina. REUNIÃO ANUAL DA SOCIEDADE BRASILEIRA DE ZOOTECNIA, 39., 2002, Recife. Anais... Recife, 2002b, CD-ROM.

OLIVEIRA, M.V.M. Utilização do ionóforo monensina sódica na alimentação de ruminantes. Viçosa, MG: Universidade Federal de Viçosa, 2003. 110p. Tese (Doutorado em Zootecnia) - Universidade Federal de Viçosa, 2003.

PAISLEY, S.I.; HORN, G.W. Effect of ionophore on rumen characteristics, gas production, and occurrence of bloat in cattle grazing winter wheat pasture. Animal Science Research Report Agricultural Experiment Station, Oklahoma State University, No. P-965, p.141-146, 1998.

PLAIZIER, J.C.; MARTIN, A.; DUFFIELD, T. et al. Effect of a prepartum administration of monensin in a controlledrelease capsule on apparent digestibilities and nitrogen utilization in transition dairy cows. Journal of Dairy Science, v.83, n.12, p.2918-2925, 2000.

PODSEDNICEK, M.; MAROUNEK, M. The effect of monensin on the weight gains and parameters of rumen metabolism of calves. Zivocisna Vyroba, v.36, n.10, p.857-864, 1991.

PURI, J.P.; KAPOOR, P.D.; GUPTA, M. et al. Effect of feeding monensin on some rumen metabolites and blood glucose in buffaloes. Indian Journal of Animal Science, v.64, n.1, p.88-90, 1994.

RESTLE, J.; NEUMANN, M.; ALVES FILHO, D.C. et al. Terminação em confinamento de vacas e novilhas sob dietas com ou sem monensina sódica. Revista Brasileira de Zootecnia, v.30, n.6, p.1801-1812, 2001.

ROGERS, M.; JOUANY, J.P.; THIVEND, P. et al. The effects of short-term and long-term monensin supplementation, and its subsequent withdrawal on digestion in sheep. Animal Feed Science and Technology, v.65, n.1-4, p.113-127, 1997.

RUIZ, R.; ALBRECHT, G.L.; TEDESCHI, L.O. et al. Effect of monensin on the performance and nitrogen utilization of lactating dairy cows consuming fresh forage. Journal of Dairy Science, v.84, n.7, p.1717-1727, 2001.
RUSSELL, J.B. Bactéria. "Mechanisms of ionophore action in ruminal bacteria”. Symposium Sponsored by: Elanco Animal Health. Scientific Update " On rumensin / Tylan/ Micotil for the professional feedlot consultant”, AmarilloTX, august, p.E1-E19, 1996.

RUSSELL, J.B.; STROBEL, H.J. Mini review. Effect of ionóforos on ruminal fermentation. Applied and Environmental Microbiology, v.55, p.1-6, 1989.

RUSSELL, J.B.; WALLACE, R.J. Energy-yielding and energyconsuming reactions. The rumen microbial ecosystem. 2.ed. 1997. p.267-268.

SCHULER, D. Studies on the influence of monensin-Na on the protein content of cow milk and further characteristics of performance. Archives of Animal Nutrition, v.38, n.10, p.947-954, 1988.

SILVA, D.J. Análise de alimentos: métodos químicos e biológicos. 2.ed. Viçosa, MG: Universidade Federal de Viçosa, 1990. 165p.

SINGH, G.P.; MOHINI, M. Effect of different levels of rumensin in diet on rumen fermentation, nutrient digestibility and methane production in cattle. Asian Australian Journal of Animal Sciences, v.12, n.8, p.1215-1221, 1999.

STATISTIC ANALYSIS SYSTEM - SAS. User's guide. Cary: 1997.

TOWNE, G.; NAGARAJA, T.G.; BRANDT JR., R.T. et al. Dynamics of ruminal ciliated protozoa in feedlot cattle. Applied and Environmental Microbiology, v.56, n.10, p.3174-3178, 1990.

VAGNONI, D.B.; CRAIG, W.M.; GATES, R.N. et al. Monensin and ammonization or urea supplementation of bermudagrass hay diets for steers. Journal of Animal Science, v.73, n.6, p.1793-1802, 1995.

WARD, M.G.; ADAMS, D.C.; WALLACE, J.D. et al. Supplementation and monensin effects on digesta kinetics. 2. Cattle grazing winter range. Journal of Range Management, v.43, n.5, p.383-386, 1990.

WEDEGAERTNER, T.C.; JOHNSON, D.E. Monensin effects on digestibility methanogenesis and heat increment of a cracked corn-silage diet fed to steers. Journal of Animal Science, v.57, p.168-177, 1983.

YANG, C.M.J.; RUSSELL, J.B. The effect of monensin supplementation on ruminal ammonia accumulation in vivo and the numbers of amino acid-fermenting bacteria. Journal of Animal Science, v.71, n.12, p.3470-3476, 1993.

ZHOU, G.; CLARK, R.S. Effect of Rumensin and feed intake variation on ruminal $\mathrm{pH}$ in beef cattle. Journal of Jilin Agricultural University, v.21, n.4, p.1-5, 1999.

ZINN, R.A.; BORQUES, J.L. Influence of sodium bicarbonate and monensin on utilization of a fat-supplemented, highenergy growing-finishing diet by feedlot steers. Journal of Animal Science, v.71, n.1, p.18-25, 1993.

ZINN, R.A.; PLASCENCIA, A.; BARAJAS, R. Interaction of forage level and monensin in diets for feedlot cattle on growth performance and digestive function. Journal of Animal Science, v.72, n.9, p.2209-2215, 1994. 